\title{
Silicon-Induced Cell Wall Fortification of Rice Leaves: A Possible Cellular Mechanism of Enhanced Host Resistance to Blast
}

\author{
Sang Gyu Kim, Ki Woo Kim, Eun Woo Park, and Doil Choi
}

\begin{abstract}
First and third authors: School of Agricultural Biotechnology, Seoul National University, Suwon 441-744, Korea; second author: National Instrumentation Center for Environmental Management, Seoul National University, Suwon 441-744, Korea; and fourth author: Korea Research Institute of Bioscience and Biotechnology, Taejon, 305-333, Korea.
\end{abstract}

Accepted for publication 22 May 2002.

\begin{abstract}
Kim, S. G., Kim, K. W., Park, E. W., and Choi, D. 2002. Silicon-induced cell wall fortification of rice leaves: A possible cellular mechanism of enhanced host resistance to blast. Phytopathology 92:1095-1103.

Locations of silicon accumulation in rice leaves and its possible association with resistance to rice blast were investigated by electron microscopy and X-ray microanalysis. A blast-susceptible cultivar, Jinmi, and a partially resistant cultivar, Hwaseong, were grown under a hydroponic culture system with modified Yoshida's nutrient solution containing 0,50, 100, and $200 \mathrm{ppm}$ of silicon. Electron-dense silicon layers were frequently found beneath the cuticle in epidermal cell walls of silicon-treated plants. Increasing levels of silicon were detected in the outer regions of epidermal cell walls. Silicon was present mainly in epidermal cell walls, middle lamellae, and intercellular spaces within sub-
\end{abstract}

ABSTRACT

Silicon $\left({ }^{14} \mathrm{Si}\right)$ is the second most abundant element on the surface of the earth. It is present in plants in amounts equivalent to those of certain macronutrients such as calcium, magnesium, and phosphorus (11). As a major inorganic constituent of higher plants, it is deposited in plants in the form of amorphous silica gel $\left(\mathrm{SiO}_{2} \cdot \mathrm{nH}_{2} \mathrm{O}\right)$. Grasses can be either stunted or very weak in the absence of silicon, thus silicon has been considered important for normal plant growth and development. Although there have been numerous reports on its biological roles, it is still controversial that silicon plays a direct role in the metabolism of higher plants that accumulate it in considerable quantities $(11,24)$.

Rice (Oryza sativa L.) shows the greatest uptake of silicon in the family Gramineae, accumulating silicon at 10 to $15 \%$ on a dry weight basis (11). Silicon has been reported to benefit rice in a number of ways: (i) increasing canopy photosynthesis by keeping leaves erect, (ii) increasing resistance to fungi, bacteria, and insects, (iii) reducing the toxicity of heavy metals, (iv) reducing cuticular transpiration, and (v) improving water use efficiency $(11,24,31)$. The translocation and deposition of silicon in rice are closely related to cuticular transpiration, and silicon is localized along the transpiration stream (31). Silicon is predominantly deposited in the epidermis of all tissues of rice (30). In rice leaves, silicon is deposited in the epidermis, vascular bundles plus bundle sheath, and sclerenchyma. The silicon layer forms in epidermal cell walls beneath the cuticle, which has been referred to as the cuticle-silica double layer (31). The cuticle-silica double layer in the epidermis has been suggested to control transpiration as well as prevent fungal and insect invasions.

Corresponding author: E. W. Park; E-mail address: ewpark@plantpath.snu.ac.kr

Publication no. P-2002-0808-01R

(C) 2002 The American Phytopathological Society epidermal tissues. Furthermore, silicon was prevalent throughout the leaf surface, with relatively small deposition on stomatal guard cells in silicontreated plants. Silicon accumulation and epidermal cell wall thickness in leaves were greater in cv. Jinmi than in cv. Hwaseong. However, the thickness ratios of the silicon layers to epidermal cell walls were greater in cv. Hwaseong (53.25 to $93.28 \%$ ) than in cv. Jinmi (36.58 to 66.54\%). Leaf blast severity was lower in cv. Hwaseong than in cv. Jinmi and was significantly reduced in silicon-treated plants of both cultivars. These results suggest that silicon-induced cell wall fortification of rice leaves may be closely associated with enhanced host resistance to blast.

Additional keywords: analytical electron microscopy, host defense, Magnaporthe grisea, mineral nutrition, Oryza sativa.
Previous studies showed that applications of silicon-containing fertilizers to paddy fields resulted in increased control of several economically important diseases such as blast (Magnaporthe grisea) (2,25), brown spot (Bipolaris oryzae) (9), and sheath blight (Rhizoctonia solani) (21) with improved yield and quality. The resistance levels of leaf blast were positively correlated with the amounts of calcium silicate slag applied to paddy fields (9). A blast-resistant cultivar had more silicified cells than a susceptible cultivar (19). Moreover, silicon sources have residual effects that persist in soils over time, which might reduce subsequent applications considerably after the first treatment (8).

However, the mechanisms by which silicon reduces disease development have not been well established (18). The enhanced host resistance of silicon-treated plants has been suggested to be the consequences of a greater resistance to pathogen penetration of host tissues due to the accumulation and polymerization of silicic acid $\left[\mathrm{Si}(\mathrm{OH})_{4}\right]$ in host cell walls $(13,14,31)$. Such polymerized layers have been hypothesized to physically block penetration by plant pathogenic fungi. In contrast, other works $(5-7,12)$ contended that silicon might induce host resistance by triggering a cascade of defense mechanisms of plants, leading to the accumulation of antifungal compounds such as phytoalexins and pathogenesis-related proteins in plants other than rice. Although silicon has been reported to exist in rice leaves as a structural component of cell walls by histochemical methods $(30,31)$, its precise localization has not been verified by X-ray microanalysis with electron microscopy. The advent of X-ray microanalysis has greatly clarified our knowledge of silicon localization and its biological role in higher plants by nondestructively identifying the elemental composition of specimens $(22,32)$. Particularly, energy-dispersive $\mathrm{X}$-ray microanalysis (EDX) and wavelength-dispersive X-ray microanalysis (WDX) have been primarily employed for obtaining qualitative and quantitative information on the elemental 
composition of specimens, respectively. In situ localization and quantitative analysis of silicon deposition under varying silicon concentrations will provide a better understanding of mechanisms of silicon-induced resistance to rice leaf blast. The objectives of this study were to (i) examine ultrastructural modification of rice leaves after silicon applications, (ii) localize silicon deposition in rice leaves, and (iii) determine if a cellular mechanism of siliconinduced resistance to rice leaf blast is apparent.

\section{MATERIALS AND METHODS}

Rice growth under a hydroponic culture system. Two rice cultivars were used in this study: (i) 'Jinmi', a susceptible cultivar to leaf blast, and (ii) 'Hwaseong', a partially resistant cultivar to leaf blast. Seeds of the two cultivars were sterilized with $0.05 \%$ prochloraz ( $N$-propyl- $N$-(2-(2,4,6-trichlorophenoxy)ethyl)-imidazole1-carboxamide) overnight and washed thoroughly with distilled water. The seeds were immersed in distilled water and kept at $28^{\circ} \mathrm{C}$ under continuous darkness for 3 days. Germinated seeds were then sown in holes of polystyrene plates containing vermiculite and maintained at $28^{\circ} \mathrm{C}$ under continuous darkness for 2 days. The plates were floated in plastic trays $\left(48 \times 38 \times 10 \mathrm{~cm}^{3}\right)$ so that roots were immersed in distilled water. Seedlings were transferred to, and grown under, a hydroponic culture system with modified Yoshida's nutrient solution (29) with silicon. Twenty thousand parts per million (ppm) of sodium silicate solution No. 1 (Showa

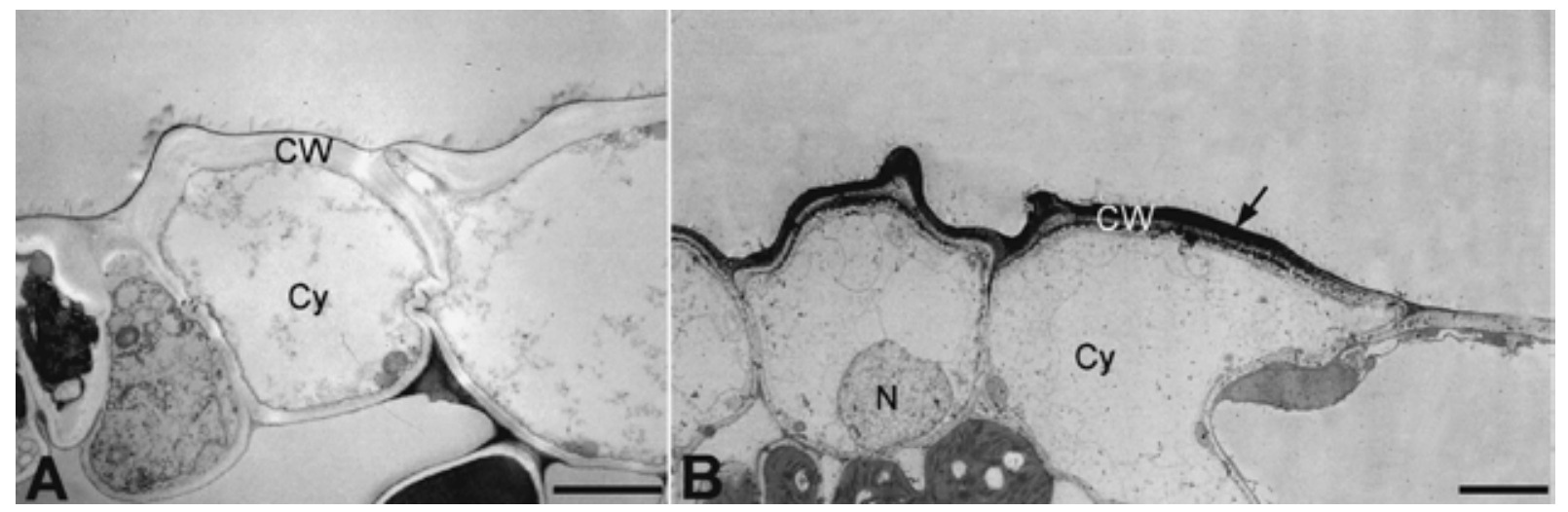

Fig. 1. Transmission electron micrographs of rice (cv. Jinmi) leaves at the 4-leaf growth stage. A, Epidermal cells of a control plant. $\mathrm{CW}=\mathrm{cell}$ wall, $\mathrm{Cy}=$ cytoplasm. Bar $=2 \mu \mathrm{m}$. B, Epidermal cells of a silicon-treated $(200 \mathrm{ppm}$ ) plant. An electron-dense layer (an arrow) is evident in the epidermal cell wall (CW). $\mathrm{N}=$ nucleus. $\mathrm{Bar}=3 \mu \mathrm{m}$.
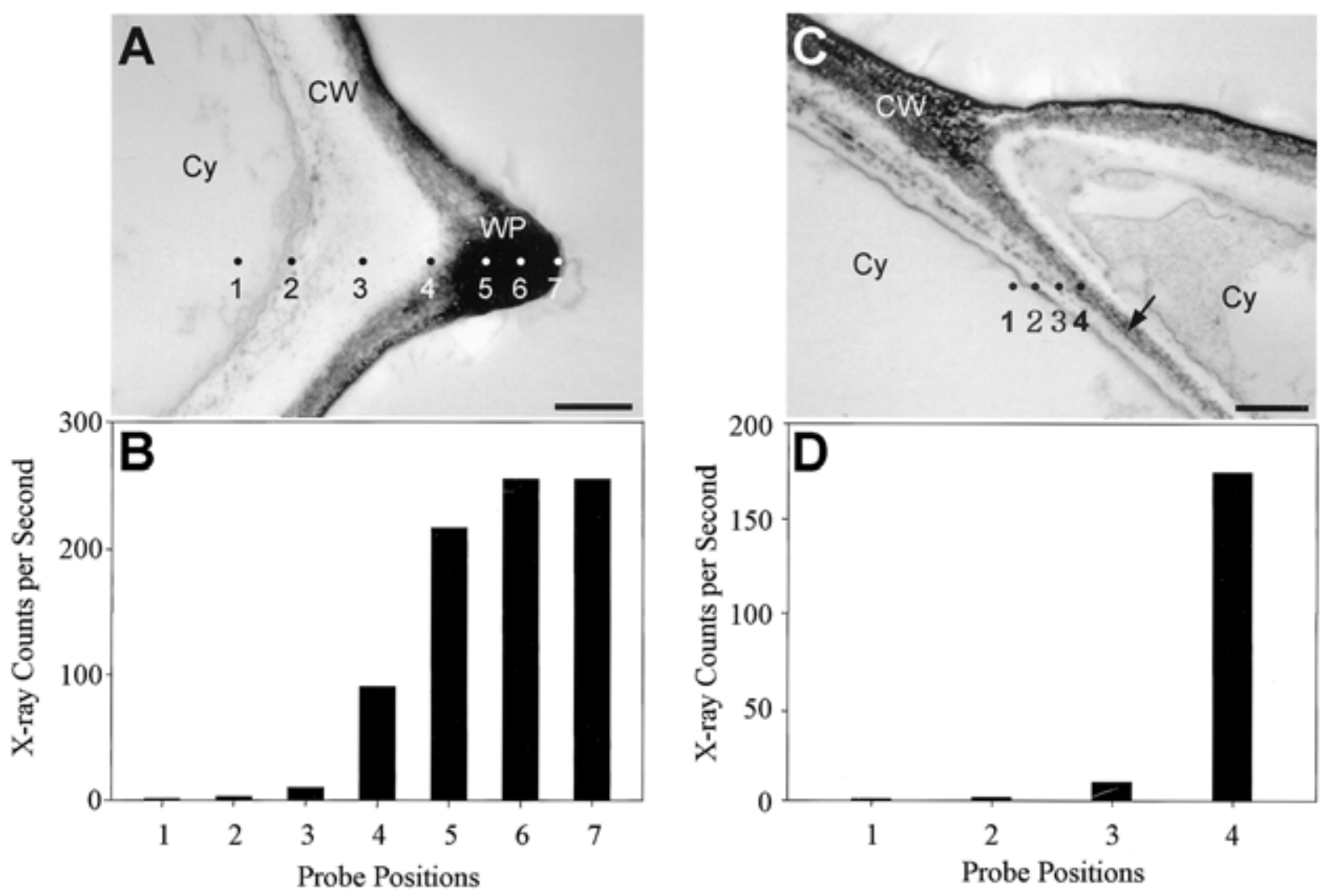

Fig. 2. Transmission electron micrographs and X-ray spectra of silicon-treated (200 ppm) rice (cv. Jinmi) leaves at the 4-leaf growth stage. A, An epidermal cell wall $(\mathrm{CW})$ with a wart-like protuberance (WP). Numbers in the micrograph indicate the probe positions for X-ray emission. Cy $=$ cytoplasm. Bar $=1 \mu \mathrm{m}$. B, Xray counts of silicon at the probe positions in A. C, Epidermal cells. Note the electron-dense middle lamella (an arrow) between the two cells. Numbers in the micrograph indicate the probe positions for X-ray emission. Bar $=0.5 \mu \mathrm{m}$. D, X-ray counts of silicon at the probe positions in $\mathbf{C}$. 
Chemical Co., Tokyo) was first prepared with distilled water, and then appropriate amounts of sodium silicate solution were added to Yoshida's nutrient solution to make 0, 50, 100, and $200 \mathrm{ppm}$ of silicon concentrations, respectively. The water used to make modified Yoshida's nutrient solution with no added silicon contained $0.74 \mathrm{ppm}$ of silicon, which was determined by an inductively coupled plasma emission spectrometer (ICPS-1000IV; Shimadzu Co., Tokyo). The nutrient solution was renewed once a week, and the $\mathrm{pH}$ of the solution was adjusted to 5.0 by adding $1 \mathrm{~N} \mathrm{HCl}$. This experiment was carried out in a greenhouse, and rice plants of both cultivars were grown until the 12-leaf growth stage when panicles were initiated.

Transmission electron microscopy. Squares (each $1 \times 3 \mathrm{~mm}^{2}$ ) were excised with scissors from a midportion of the youngest fully extended rice leaves at the 4-, 8-, and 12-leaf growth stages. The specimens were fixed with modified Karnovsky's fixative consisting of $2 \%(\mathrm{vol} / \mathrm{vol})$ glutaraldehyde and $2 \%(\mathrm{vol} / \mathrm{vol})$ paraformaldehyde in $0.05 \mathrm{M}$ sodium cacodylate buffer $(\mathrm{pH} 7.2)$ at $4^{\circ} \mathrm{C}$ overnight and washed with the same buffer three times for $10 \mathrm{~min}$ each. The specimens were postfixed with $1 \%$ (wt/vol) osmium tetroxide in the same buffer at $4^{\circ} \mathrm{C}$ for $2 \mathrm{~h}$ and washed with distilled water two times briefly. The postfixed specimens were en bloc stained with $0.5 \%$ (wt/vol) uranyl acetate at $4^{\circ} \mathrm{C}$ overnight. They were dehydrated in a graded ethanol series $(30,50,70,80$, 95 , and $100 \%$ ) and three times in $100 \%$ ethanol for 10 min each. The specimens were further treated with propylene oxide as a transitional fluid two times for $30 \mathrm{~min}$ each and embedded in Spurr's medium. Ultrathin sections (approximately $50 \mathrm{~nm}$ thick) were made with a diamond knife by an ultramicrotome (MT-X; RMC Inc., Tucson, AZ). The sections were mounted on copper grids and stained for 7 min each with $2 \%$ uranyl acetate and Reynolds' lead citrate (20). The sections were examined by transmission electron microscopy (TEM) (JEM-1010; JEOL Ltd., Tokyo) at an accelerating voltage of $80 \mathrm{kV}$. Electron micrographs were recorded and digitalized using an image processing system (FDL 5000; Fuji Photo Film Ltd., Tokyo). For each specimen, more than six ultrathin sections were examined with the microscope.

Localization of silicon deposition in rice leaves by TEM/EDX. Leaf squares for X-ray microanalysis of silicon were processed as described for TEM. Ultrathin sections were mounted on copper grids, coated with carbon, and left unstained to avoid interference by uranium and lead in X-ray microanalysis. The sections were examined by TEM (CM 30; Philips Ltd., Eindhoven, the Netherlands) at an accelerating voltage of $200 \mathrm{kV}$. Silicon deposition sites were determined by an energy-dispersive X-ray spectrometer (DX4; EDAX Ltd., Mahwah, NJ) combined with the microscope. Several points in the ultrathin sections of leaves were randomly selected and probed for X-ray emission. X rays were collected with a detector fixed at a take-off angle of $45^{\circ}$, and their spectra were recorded during a process time of $60 \mathrm{~s}$ per point. Results of the analysis were presented as X-ray spectra, and elemental peaks at the position of $1.74 \mathrm{keV}$ were regarded as $\mathrm{K}$ alpha $\mathrm{X}$-ray signal of silicon (15). X-ray intensities of each element were recorded in counts per second (CPS).

Localization of silicon deposition in rice leaves by scanning electron microscopy/EDX. Squares (each $5 \times 10 \mathrm{~mm}^{2}$ ) were excised from a midportion of the youngest fully extended leaves at the 6-leaf growth stage. The specimens were fixed, postfixed, and dehydrated as described for TEM. They were further treated with hexamethyldisilazane two times for $15 \mathrm{~min}$ each and air dried. The specimens were mounted on copper-zinc alloy stubs, coated with gold, and examined by SEM (JSM-5410LV; JEOL Ltd.) at an accelerating voltage of $20 \mathrm{kV}$. Silicon deposition sites were determined by point analysis with an energy-dispersive $\mathrm{X}$-ray spec-
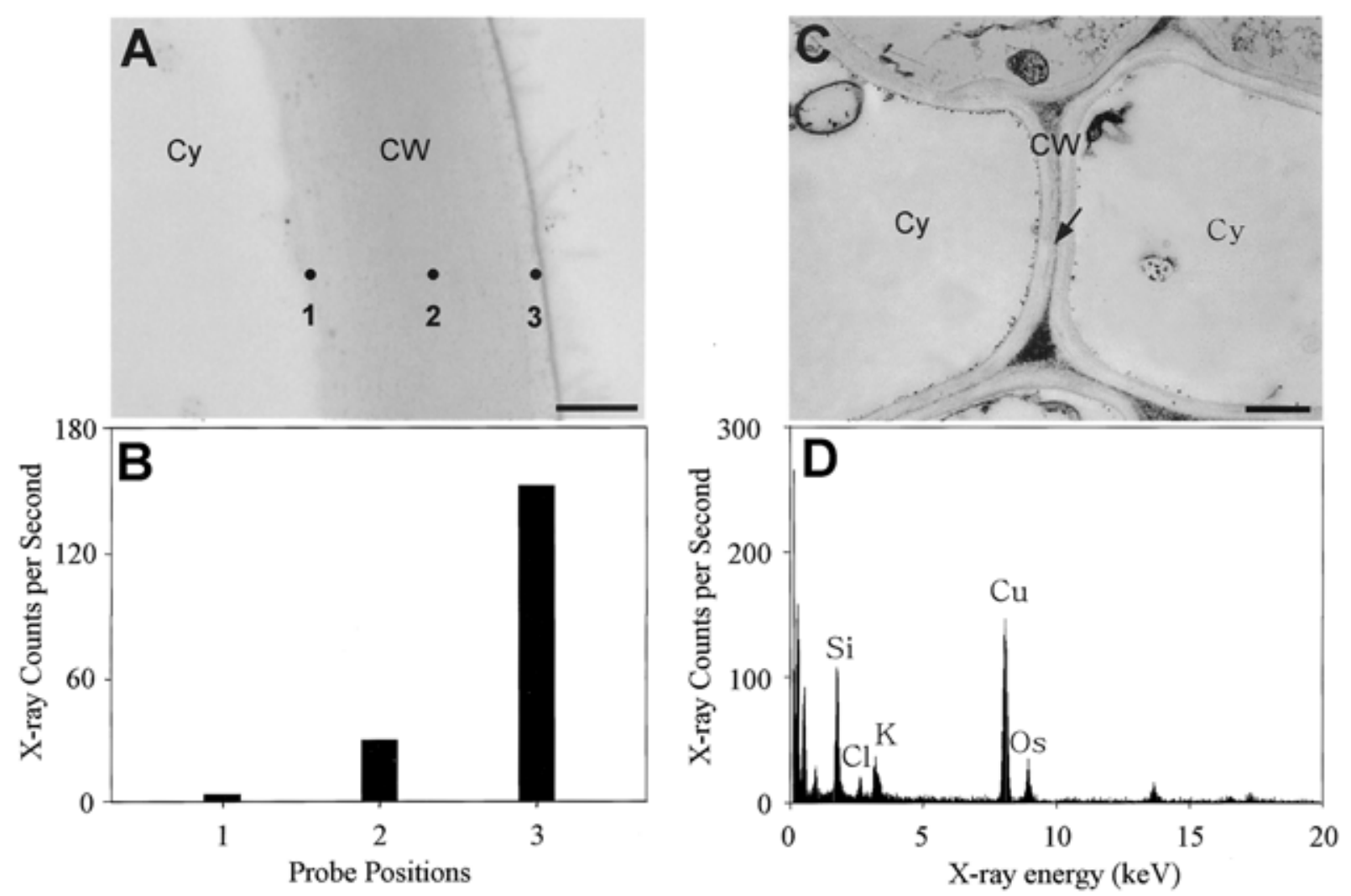

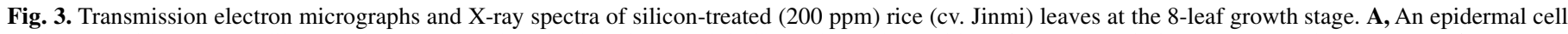

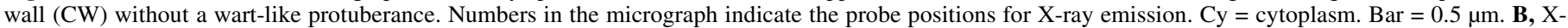

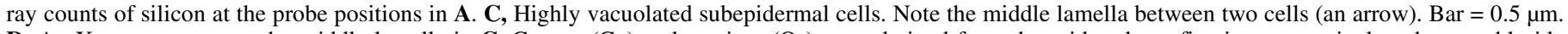

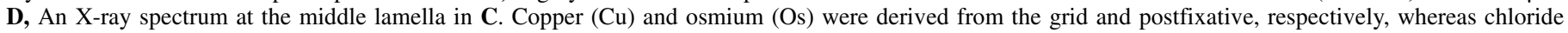
$(\mathrm{Cl})$ and potassium $(\mathrm{K})$ were derived from rice plants grown with the nutrient solution containing the elements. 
trometer (Link ISIS; Oxford Ltd., Buckinghamshire, UK) combined with the microscope. Secondary electron images were acquired, and several points on the leaf surface were randomly selected and probed for X-ray emission. To observe the overall distribution pattern of silicon, secondary electron images and their corresponding X-ray maps of silicon were also obtained for mapping analysis with the SEM. $X$ rays were collected with a detector fixed at a take-off angle of $30^{\circ}$, and their spectra were recorded during a process time of $60 \mathrm{~s}$ per point.

Quantitative analysis of silicon levels in rice leaves by WDX. Leaf squares (each $5 \times 10 \mathrm{~mm}^{2}$ ) were sampled from three height positions (second, fourth, and sixth leaf) and two surfaces (adaxial and abaxial) of two cultivars with four concentrations of silicon at the 6-leaf growth stage. They were then processed as SEM to quantify the relative levels of silicon in rice leaves. The levels were measured by a wavelength-dispersive X-ray spectrometer in an electron probe microanalyzer (JXA-8600; JEOL Ltd.) at an accelerating voltage of $15 \mathrm{kV}$. Four sites per leaf surface were randomly selected per height position, and six leaves per cultivar with each silicon concentration were probed for X-ray emission at $\times 1,000$ magnification. X-ray spectra of silicon were recorded during a process time of $60 \mathrm{~s}$ per site at the probe current of $1.0 \times$ $10^{-8} \mathrm{~A}$. The relative levels of silicon were expressed as a ratio of silicon CPS of a specimen to those of standard silicon. Data from each treatment were pooled to calculate and compare mean relative levels of silicon per cultivar among silicon concentrations by Fisher's protected least significant difference (FLSD) test using SAS PROC GLM (SAS Institute, Cary, NC).

Thickness measurement of cell wall and silicon layer in leaf epidermis. Transmission electron micrographs of leaf epidermis at the 4-leaf growth stage were taken to measure the thickness of the cell wall and silicon layer, respectively. Epidermal cell wall thickness was measured by an image analyzer (analySIS; Soft Imaging System GmbH Ltd., Münster, Germany). In addition, the thickness of electron-dense layers of epidermal cell walls was measured as thickness of silicon layers as defined previously (31). Ten measurements were taken on each micrograph, a total of 6 to 40 micrographs per cultivar with each silicon concentration. Treatment means were calculated and compared among treatments by FLSD.

Pathogenicity test. Two isolates of M. grisea (KI-197 and KI-409) were used in this study. The fungi were grown on oatmeal agar plates and incubated at $25^{\circ} \mathrm{C}$ under fluorescent light with a 12-h photoperiod for 2 weeks. Conidia were dislodged by flooding the plates with sterilized distilled water amended with Tween 80 at $250 \mathrm{ppm}$ and scraping the plate surface. The sus-

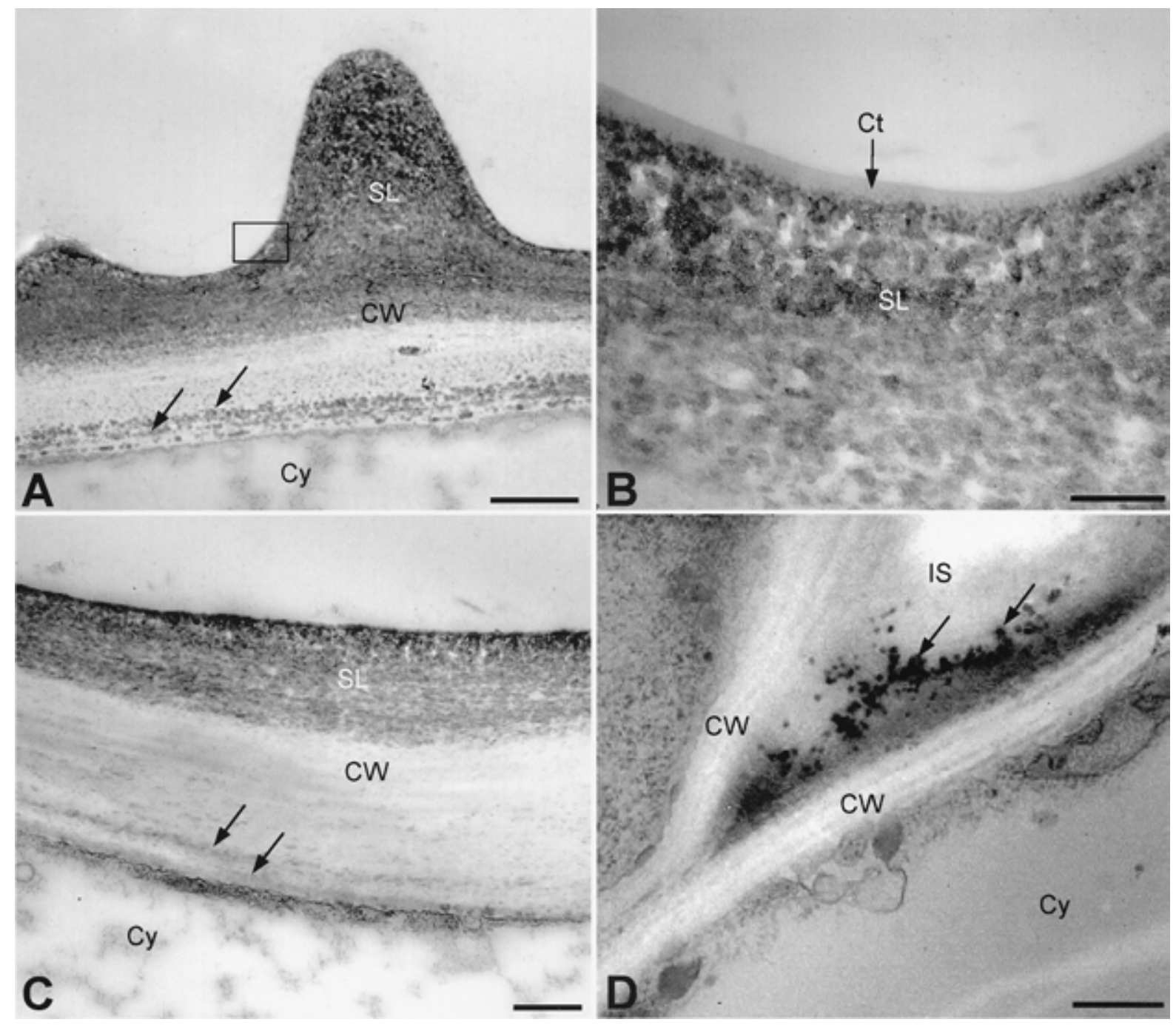

Fig. 4. Transmission electron micrographs of silicon-treated (200 ppm) rice (cv. Jinmi) leaves at the 12-leaf growth stage. A, An epidermal cell wall (CW) with an electron-dense silicon layer (SL). Thin silicon layers (arrows) are embedded in the inner electron-translucent region of the epidermal cell wall. Cy $=$ cytoplasm. Bar $=1 \mu \mathrm{m}$. B, A higher magnification of the rectangle in A. The cuticle (Ct) (an arrow) is found above the electron-dense silicon layer (SL). Note electron-dense polymorphic aggregates in the silicon layer. Bar $=0.2 \mu \mathrm{m}$. C, An epidermal cell wall $(\mathrm{CW})$ without a wart-like protuberance. An electron-dense silicon layer (SL) and thin silicon layers (arrows) are also observed as in $\mathbf{A}$. Bar $=0.5 \mu \mathrm{m}$. D, Electron-dense silicon aggregates (arrows) in the intercellular space (IS) within a subepidermal tissue. $\mathrm{CW}=$ cell wall. $\mathrm{Bar}=0.5 \mu \mathrm{m}$. 
pension was filtered through three layers of cheesecloth to remove mycelial fragments. Inoculum concentration of the conidial suspension was adjusted to $5 \times 10^{5}$ conidia per ml using a hemacytometer. Conidial suspension was sprayed onto at least 13 rice plants per cultivar at the 6-leaf growth stage. Immediately after inoculation, the plants were placed in a dew chamber at $25^{\circ} \mathrm{C}$ for 1 day. They were then kept at $25^{\circ} \mathrm{C}$ under $80 \%$ relative humidity for 3 days. Every leaf of each plant was examined, and disease severity was expressed as mean percentage of diseased leaf areas. This experiment was repeated three times on different days. Data from each experiment were pooled to calculate and compare mean disease severity among treatments by FLSD.

\section{RESULTS}

TEM of rice leaves showed epidermal cells with wart-like protuberances on cell walls in control plants and silicon-treated plants, respectively (Fig. 1A and B). Epidermal cell walls of control plants did not exhibit high electron-dense areas; however, thick electron-dense areas were frequently found in the outer region of epidermal cell walls of silicon-treated plants. Such layers were not uniformly distributed along epidermal cell walls.

Localization of silicon deposition in rice leaves by TEM/EDX. Analysis from TEM/EDX indicated that silicon was present in epidermal cell walls, middle lamella, and intercellular spaces of silicon-treated plants regardless of the leaf growth stages tested. At the 4-leaf growth stage, electron-dense layers were evident in the outer region of epidermal cell walls having wart-like protuberances (Fig. 2A). X-ray counts of silicon increased as probe positions progressed from the inner side of epidermal cell walls outward, showing the highest count in the electron-dense outermost region of cell walls (Fig. 2B). Almost no silicon was detected within the cytoplasm compared with that in epidermal cell walls. Beneath the epidermis, electron-dense regions were found also in middle lamella (Fig. 2C). X-ray microanalysis revealed silicon deposition in middle lamella, and low levels of silicon were detected in the neighboring cell walls (Fig. 2D).

At the 8-leaf growth stage of silicon-treated plants, electrondense layers were evident in the outer regions of epidermal cells and silicon was detected in those regions (data not shown). Some epidermal cell walls without wart-like protuberances did not show high electron density (Fig. 3A). X-ray counts of silicon increased as probe positions progressed from the inner side of the epidermal cell wall outward (Fig. 3B). In addition, silicon was detected in electron-dense middle lamella within subepidermal tissues (Fig. 3C and D). Traces of other elements including copper were also detected. The copper peak was due to copper in the grids on which specimens were mounted for electron microscopy. In contrast, various positions of neighboring normal cytoplasm were probed for X-ray emission, and silicon was not detected within the cytoplasm regardless of the probe positions (data not shown).

At the 12-leaf growth stage of silicon-treated plants, epidermal cell walls with wart-like protuberances were frequently found (Fig. 4A). The epidermal cell walls consisted of an electron-dense silicon layer, approximately 1 to $3.5 \mu \mathrm{m}$ thick, and an electrontranslucent inner layer. The inner layer appeared to be further differentiated and filled with silicon, forming thin electron-dense silicon layers embedded in cellulose microfibrils along the cell walls. The cuticle, approximately $45 \mathrm{~nm}$ thick, was evident above the electron-dense silicon layer of epidermal cell walls at a higher magnification (Fig. 4B). Numerous electron-dense polymorphic aggregates were deposited within the silicon layer. Epidermal cell walls without wart-like protuberances also had electron-dense silicon layers (Fig. 4C). Thin electron-dense silicon layers were consistently found in the inner side of the cell wall. In intercellular spaces, electron-dense polymorphic aggregates were frequently observed within subepidermal tissues (Fig. 4D). These aggregates were found to contain silicon by X-ray microanalysis (data not shown).

Localization of silicon deposition on rice leaf surface by SEM/EDX. SEM of rice leaves showed that there were numerous trichomes, wart-like protuberances, and stomata on the surface (Fig. 5A). There were differences in silicon X-ray counts from points on the leaf surface of silicon-treated plants. Point analysis of silicon $X$ ray on the surface of silicon-treated plants revealed that silicon was present in both trichomes and wart-like protuberances (Fig. 5B and C). Epidermal regions without wart-like protuberances and stomatal guard cells accumulated relatively small levels of silicon compared with trichomes and wart-like protuberances (Fig. 5D and E). Traces of other elements including gold were also detected. The gold peak came from the gold coating of specimens.

X-ray mapping of silicon on the surface of rice leaves showed that X-ray counts of silicon, which were imaged as white dots, were hardly observed from the leaf surface of control plants (Fig. $6 \mathrm{~A}$ and B). The dark empty area in Figure 6B represents the absence of silicon on the same leaf surface in Figure 6A. In the case of silicon-treated plants, however, silicon was present throughout

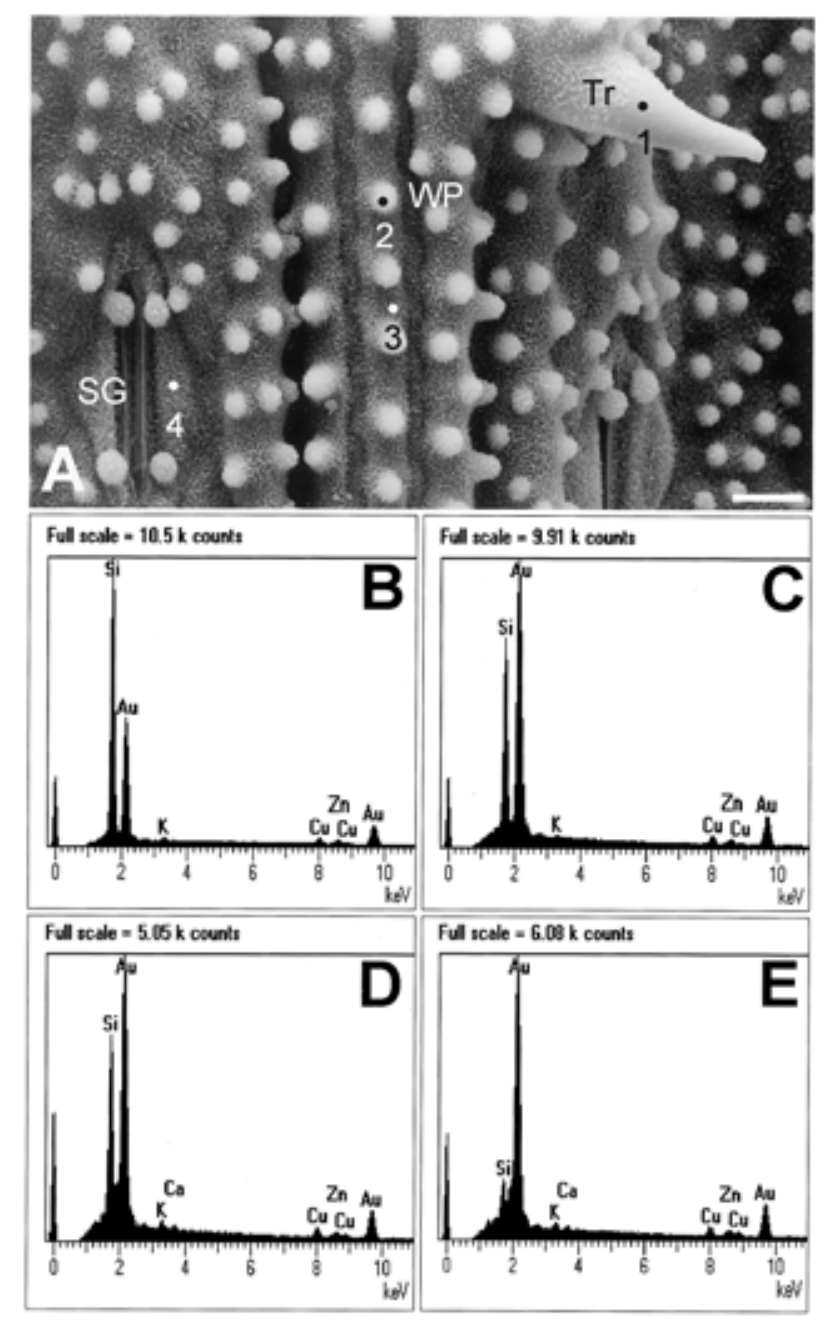

Fig. 5. A scanning electron micrograph and X-ray spectra of silicon-treated (200 ppm) rice (cv. Jinmi) leaves at the 6-leaf growth stage. A, The surface of a leaf. Numbers in the micrograph indicate the probe positions for X-ray emission. $\mathrm{SG}=$ stomatal guard cell, $\mathrm{Tr}=$ trichome, $\mathrm{WP}=$ wart-like protuberance. $B a r=10 \mu \mathrm{m}$. B to $\mathbf{E}, X$-ray spectra at the probe positions $(1,2,3$, and 4 ) in A, respectively. Gold (Au) was derived from the coating material, whereas copper $(\mathrm{Cu})$ and zinc $(\mathrm{Zn})$ were derived from the metal stub. Potassium $(\mathrm{K})$ and calcium $(\mathrm{Ca})$ were derived from rice plants grown with the nutrient solution containing the elements. 
the leaf surface with apparently low silicon X-ray counts around stomatal guard cell areas (Fig. 6C and D). High X-ray counts of silicon coincided generally with the areas protruded on the leaf surface.

Quantitative analysis of silicon levels in rice leaves by WDX. $\mathrm{X}$-ray microanalysis revealed that significant levels of silicon were present in rice leaves (Fig. 7). In control plants, small levels of silicon were detected in both cultivars. Approximately five to eight times greater levels of silicon were found in silicon-treated plants of both cultivars than in control plants depending on silicon concentrations in modified Yoshida's nutrient solution. However, silicon accumulation, which was measured as X-ray CPS, was greater in cv. Jinmi than in cv. Hwaseong by 12 to $43 \%$ depending on silicon concentrations in the nutrient solution. There was no significant difference in silicon levels in cv. Jinmi between plants treated with 100 and $200 \mathrm{ppm}$ of silicon $(P=0.01)$. In addition, no further increases in silicon levels were observed in silicon-treated plants of cv. Hwaseong. There was also no significant difference in silicon levels among silicon-treated plants of cv. Hwaseong $(P=0.01)$.

Thickness measurement of cell wall and silicon layer in leaf epidermis. Epidermal cell wall thickness did not show consistent patterns with the increasing silicon concentrations in both cultivars (Fig. 8A). Epidermal cell walls in cv. Jinmi (508.88 to $1,105.50 \mathrm{~nm}$ ) were generally thicker than epidermal cell walls in cv. Hwaseong (435.82 to $678.23 \mathrm{~nm}$ ). Silicon-treated cv. Jinmi had thicker epidermal cell walls than control plants. Cell wall thickness of cv. Hwaseong was not significantly affected by the silicon applications. Electron-dense silicon layers were easily discernible in epidermal cell walls of silicon-treated plants, whereas the layers were not observed in control plants (Fig. 8B). The silicon layer of the two cultivars exhibited similar thickness in epidermal cell walls in silicon-treated plants: 345.55 to $563.70 \mathrm{~nm}$ in cv. Jinmi and 316.72 to $558.98 \mathrm{~nm}$ in cv. Hwaseong. A gradual increase in silicon layer thickness was evident in cv. Jinmi with an increase in silicon concentration in the nutrient solution. Consequently, the thickness ratios of the silicon layers to epidermal cell walls increased gradually with the increasing silicon concentrations in both cultivars (Fig. 8C). The ratios in cv. Hwaseong (53.25 to $93.28 \%$ ) were higher than the ratios in cv. Jinmi (36.58 to $66.54 \%)$ in all silicon-treated plants. There were significant

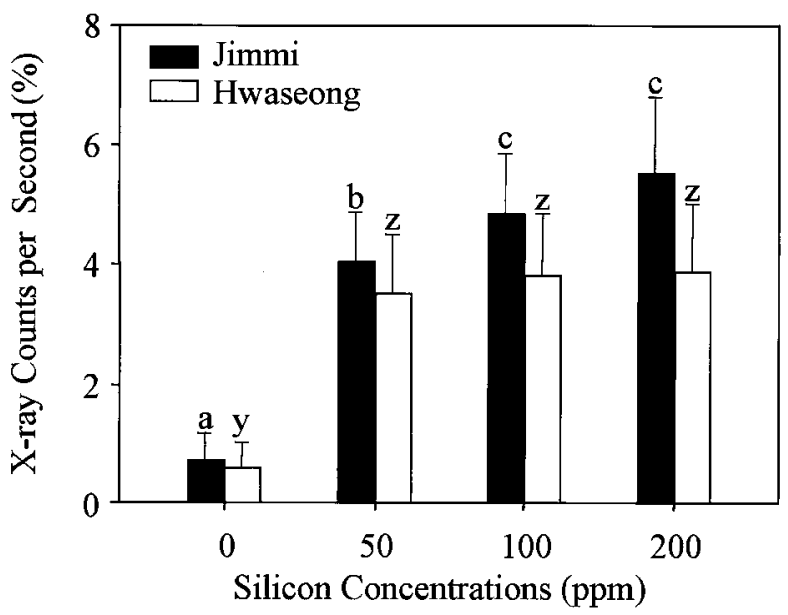

Fig. 7. Relative levels (counts per second) of silicon in rice leaves of two cultivars at the 6-leaf growth stage. Bars in the columns indicate the standard deviations. The same letter denotes no significant difference at $P=0.01$ according to Fisher's protected least significant difference test.
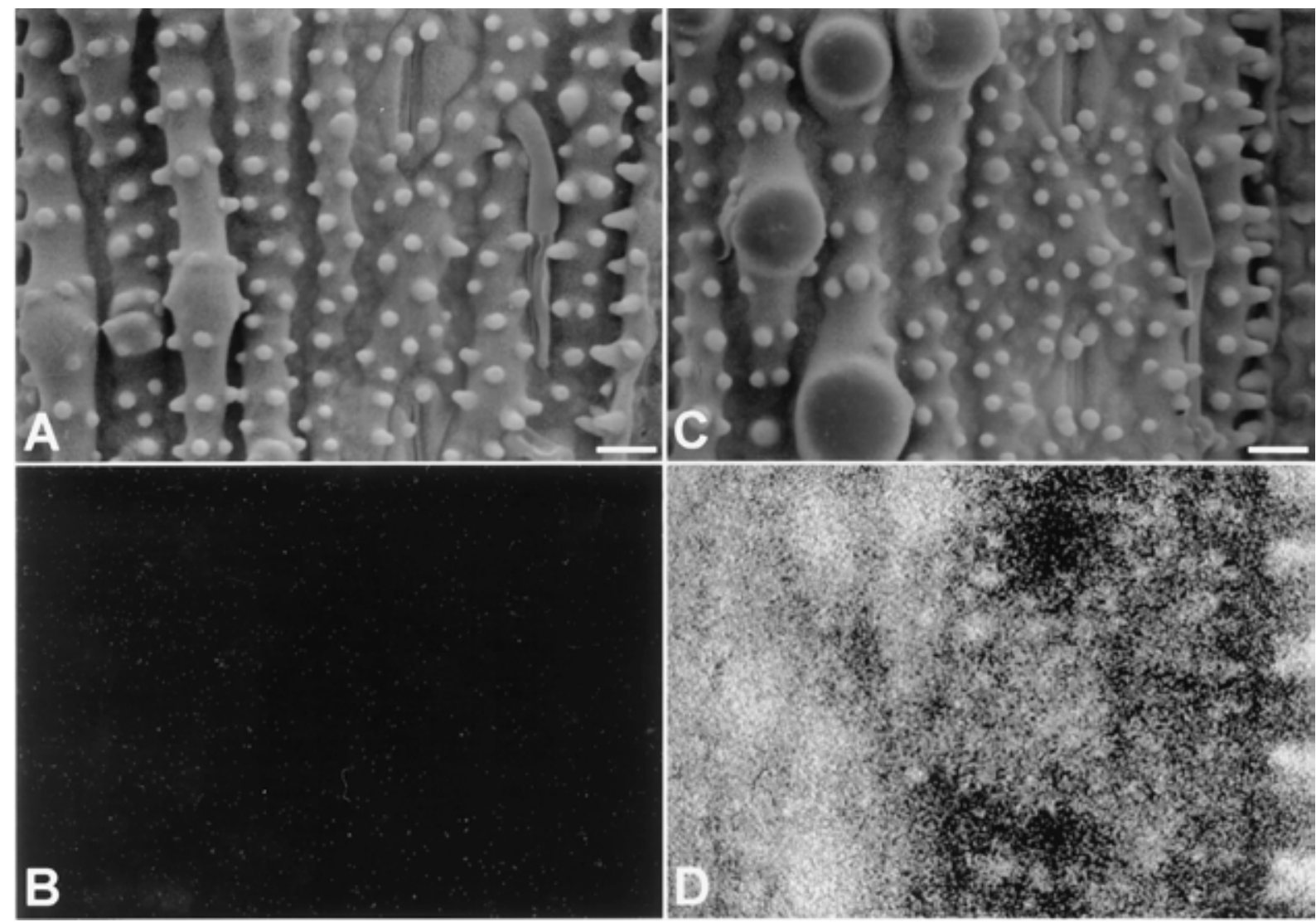

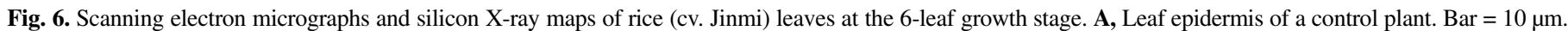

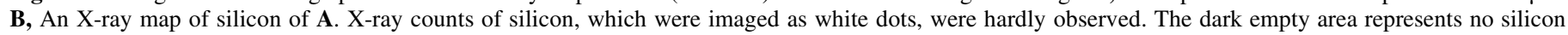

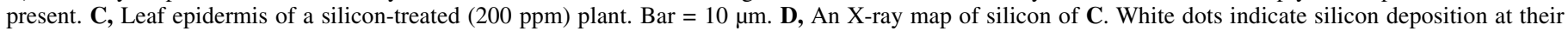
corresponding positions of the specimen. 
differences in the thickness ratios among treatments for both cultivars $(P=0.01)$.

Pathogenicity test. Silicon applications resulted in a decrease in leaf blast development in both cultivars. Mean disease severity was $4.96 \%$ in control plants of cv. Jinmi inoculated with KI-409 (Fig. 9A). Significant reductions in disease severity were found in silicon-treated plants of cv. Jinmi, showing a mean disease severity of less than $1.60 \%$. There were no significant differences in disease severity among silicon-treated plants of cv. Jinmi $(P=$ 0.01). KI-197 was less virulent to cv. Jinmi than KI-409, and cv. Jinmi inoculated with KI-197 also showed reduced disease severity in silicon-treated plants. In addition, cv. Hwaseong inoculated with the two isolates exhibited lower disease severity than cv. Jinmi (Fig. 9B). Significant reduction in disease severity was also evident in the silicon-treated plants of cv. Hwaseong regardless of fungal isolates. No significant differences in disease severity were found among silicon-treated plants of cv. Hwaseong $(P=0.01)$.

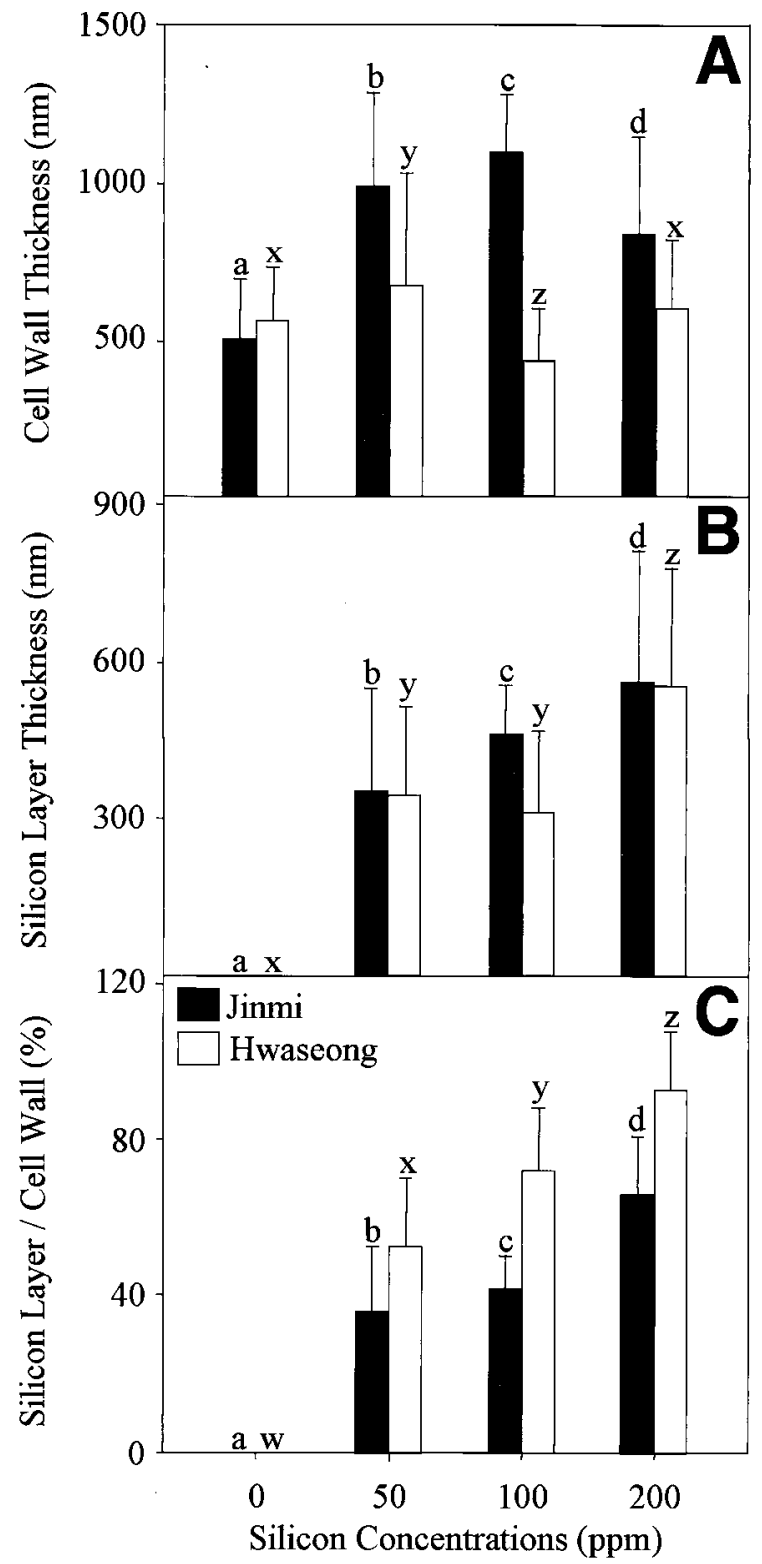

Fig. 8. Thickness of epidermal cell walls and silicon layers in rice leaves of two cultivars at the 4-leaf growth stage. A, Epidermal cell wall thickness. B, Silicon layer thickness. C, Thickness ratios of the silicon layers to epidermal cell walls. Bars in the columns indicate the standard deviations. The same letter denotes no significant difference at $P=0.01$ according to Fisher's protected least significant difference test.

\section{DISCUSSION}

Electron microscopy and in situ X-ray microanalysis in this study provided evidence that silicon was deposited in epidermal cell walls, middle lamellae, and intercellular spaces within subepidermal tissues of silicon-treated rice leaves. However, silicon was not detected in the cytoplasm of silicon-treated plants. The most striking differences between silicon-treated rice plants and control plants were found in epidermal cell wall structure. An epidermal cell wall of silicon-treated rice plants was frequently composed of two distinct layers: an outer electron-dense silicon layer and an inner electron-translucent layer often having thin electron-dense silicon layers embedded in cellulose microfibrils. Silicon localization in rice leaf tissues was first verified in this study by X-ray microanalysis with TEM. These findings were consistent with the epidermal cell wall structure in silicon-treated rice leaves described by previous authors (31). Furthermore, this study showed that silicon deposition was not restricted to electron-dense epidermal cell walls, and was detected in middle lamella and intercellular spaces as polymorphic aggregates. In spite of its amorphous nature in chemistry, silicon has been assumed to be associated with cell wall components such as polysaccharides and proteins (3). It is likely that silicon was incorporated into cell walls as silicon-aromatic ring associations between lignin and carbohydrate in rice leaves $(16,17)$. These organo-silicon compounds in epidermal cell walls have been suggested to play a role in limiting lesion expansion (28), which may reduce the infection efficiency (the number of sporulating lesions) and inoculum production for

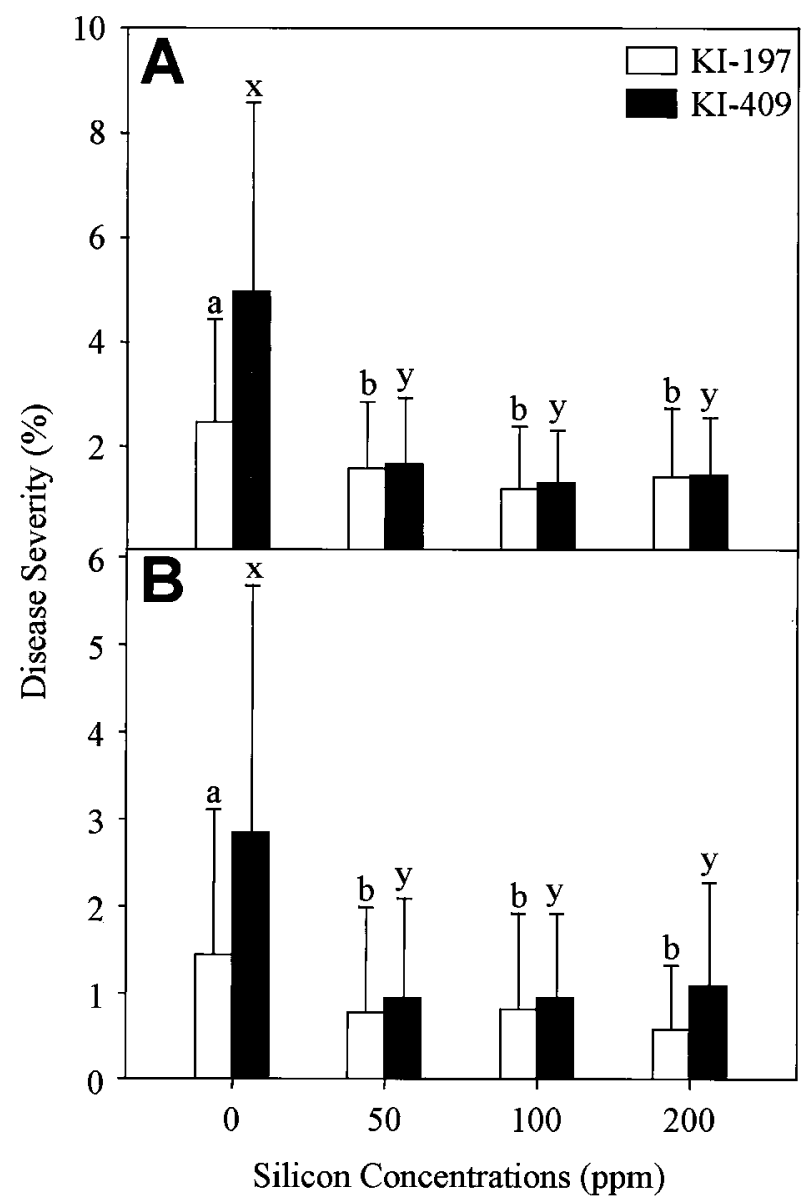

Fig. 9. Leaf blast severity of A, cv. Jinmi and B, cv. Hwaseong inoculated with two fungal isolates at the 6-leaf growth stage. Bars in the columns indicate the standard deviations. The same letter denotes no significant difference at $P=0.01$ according to Fisher's protected least significant difference test. 
secondary infection cycles of $M$. grisea in silicon-treated rice plants (26).

In addition, silicon deposition was not uniform in epidermal cell walls with increasing X-ray counts of silicon toward the outer regions of epidermal cell walls. Such differential deposition can be explained by silicon translocation in rice plants through cuticular transpiration $(10,23,27)$. Although most water escapes through stomata, some water diffuse out through epidermal cells and cuticle. Accordingly, silicon is translocated to the epidermis with water and constantly being deposited at the epidermis after transpiration. As rice plants become mature, silicon deposition is likely to become prevalent in the apoplast of rice plants.

Another feature of silicon-treated rice plants is the silicon distribution on the leaf surface as a glass-like coating. The mapping analysis of silicon on the leaf surface of silicon-treated plants showed that silicon deposition was also prevalent throughout the leaf surface with relatively small deposition on stomatal guard cell areas. Relatively high X-ray counts of silicon from the protruded areas like trichomes and wart-like protuberances on the leaf surface were partly due to X-ray intensities affected by the surface topography of rice leaves in the analysis (32). The major difference in X-ray counts from several points on the leaf surface may be from the variation in transpiration rate from each point (10). On the contrary, silicon deposition was hardly detected in cell walls of silicon-treated cucumber plants and uneven, primarily concentrated in the trichome bases $(6,7,22)$. Such uneven deposition of silicon may support the previous observation that silicon-treated cucumber plants were readily penetrated by Pythium ultimum hyphae after inoculation (7).

It is assumed in this study that silicon layers in epidermal cell walls can confer enhanced host resistance to blast. Epidermal cell wall thickness in leaves did not show consistent patterns in both cultivars. On the other hand, silicon layer thickness and the thickness ratios of the silicon layers to epidermal cell walls for both cultivars increased with increasing silicon concentrations in the nutrient solution, and the thickness ratios were greater in cv. Hwaseong than in cv. Jinmi. These facts support the idea that silicified epidermal cell walls are closely associated with the significantly reduced blast severity in both cultivars. Hwaseong appears to have a higher capacity to form silicified epidermal cell walls than cv. Jinmi. Because no further decrease in disease severity was observed with increasing silicon concentrations in either cultivar, it is likely that there would exist a threshold level of silicon needed for enhancing host resistance. As suggested previously (26), these pathogenicity data indicate the possibility that silicon applications to susceptible cultivars can raise the apparent level of resistance to that of partially resistant cultivars grown without silicon treatments with similar control of rice leaf blast.

Silicon has been implicated as a factor influencing the degree of plant resistance to biotic or abiotic stresses $(11,24)$. Presumably, silicon accumulation on leaf surface and in epidermal cell walls, middle lamellae, and intercellular spaces might limit fungal penetration and invasion by acting as a physical barrier. However, this study does not exclude the possibility that silicon may enhance host resistance by triggering local or systemic defense mechanisms in rice plants $(1,4)$. Plant responses to silicon applications are of multicomponent nature (5) and appear to be involved in a variety of biological phenomena of the plant. Elucidation of signal transduction pathways for an array of defense-related responses and their implication with the formation and functions of silicon layers could enhance our understanding of the nature of disease resistance mechanisms in rice.

\section{ACKNOWLEDGMENTS}

This study was supported by the Korea Science and Engineering Foundation (Project 1999-2-203-002-3). We thank S.-S. Han at the National
Institute of Agricultural Science and Technology, Rural Development Administration for providing the fungal cultures.

\section{LITERATURE CITED}

1. Aleshin, N. E., Avakyan, É. R., Dyakunchak, S. A., Aleshkin, E. P., Baryshok, V. P., and Voronkov, M. G. 1987. Role of silicon in resistance of rice to blast. Dokl. Akad. Nauk Uzb. SSR 291:217-219.

2. Bonman, J. M., Estrada, B. A., and Bandong, J. M. 1989. Leaf and neck blast resistance in tropical lowland rice cultivars. Plant Dis. 73:388-390.

3. Carpita, N. C. 1996. Structure and biogenesis of the cell walls of grasses. Annu. Rev. Plant Physiol. Plant Mol. Biol. 47:445-476.

4. Carver, T. L. W., Zeyen, R. J., and Ahlstrand, G. G. 1987. The relationship between insoluble silicon and success or failure of attempted primary penetration by powdery mildew (Erysiphe graminis) germlings on barley. Physiol. Mol. Plant Pathol. 31:133-148.

5. Chérif, M., Asselin, A., and Bélanger, R. R. 1994. Defense responses induced by soluble silicon in cucumber roots infected by Pythium spp. Phytopathology 84:236-242.

6. Chérif, M., Benhamou, N., Menzies, J. G., and Bélanger, R. R. 1992. Silicon induced resistance in cucumber plants against Pythium ultimum. Physiol. Mol. Plant Pathol. 41:411-425.

7. Chérif, M., Menzies, J. G., Benhamou, N., and Bélanger, R. R. 1992. Studies of silicon distribution in wounded and Pythium ultimum infected cucumber plants. Physiol. Mol. Plant Pathol. 41:371-385.

8. Datnoff, L. E., Deren, C. W., and Snyder, G. H. 1997. Silicon fertilization for disease management of rice in Florida. Crop Prot. 16:525-531.

9. Datnoff, L. E., Raid, R. N., Snyder, G. H., and Jones, D. B. 1991. Effect of calcium silicate on blast and brown spot intensities and yields of rice. Plant Dis. 75:729-732.

10. Dengler, N. G., and Lin, E. Y.-C. 1980. Electron microprobe analysis of the distribution of silicon in the leaves of Selaginella emmeliana. Can. J. Bot. 58:2459-2466.

11. Epstein, E. 1999. Silicon. Annu. Rev. Plant Physiol. Plant Mol. Biol. 50:641-664.

12. Fawe, A., Abou-Zaid, M., Menzies, J. G., and Bélanger, R. R. 1998. Silicon-mediated accumulation of flavonoid phytoalexins in cucumber. Phytopathology 88:396-401.

13. Heath, M. C., Howard, R. J., Valent, B., and Chumley, F. G. 1992. Ultrastructural interactions of one strain of Magnaporthe grisea with goosegrass and weeping lovegrass. Can. J. Bot. 70:779-787.

14. Heath, M. C., and Stumpf, M. A. 1986. Ultrastructural observations of penetration sites of the cowpea rust fungus in untreated and silicondepleted French bean cells. Physiol. Mol. Plant Pathol. 29:27-39.

15. Hodson, M. J., Sangster, A. G., and Parry, D. W. 1985. An ultrastructural study on the developmental phases and silicification of the glumes of Phalaris canariensis L. Ann. Bot. 55:649-665.

16. Inanaga, S., and Okasaka, A. 1995. Calcium and silicon binding compounds in cell walls of rice shoots. Soil Sci. Plant Nutr. 41:103-110.

17. Inanaga, S., Okasaka, A., and Tanaka, S. 1995. Does silicon exist in association with organic compounds in rice plant? Soil Sci. Plant Nutr. 41:111-117.

18. Ishiguro, K. 2001. Review of research in Japan on the roles of silicon in conferring resistance against rice blast. Pages 277-291 in: Studies in Plant Science, Vol. 8. Silicon in Agriculture. L. E. Datnoff, G. H. Snyder, and G. H. Korndörfer, eds. Elsevier Science, Amsterdam, The Netherlands.

19. Kwon, S. H., Oh, J. H., and Song, H. S. 1974. Studies on the relationship between chemical contents of rice plants and resistance to rice blast disease. Kor. J. Plant Prot. 13:33-39.

20. Reynolds, E. S. 1963. The use of lead citrate at high $\mathrm{pH}$ as an electronopaque stain in electron microscopy. J. Cell Biol. 17:208-212.

21. Rodrigues, F. Á., Datnoff, L. E., Korndörfer, G. H., Seebold, K. W., and Rush, M. C. 2001. Effect of silicon and host resistance on sheath blight development in rice. Plant Dis. 85:827-832.

22. Samuels, A. L., Glass, A. D. M., Ehret, D. L., and Menzies, J. G. 1991. Distribution of silicon in cucumber leaves during infection by powdery mildew fungus (Sphaerotheca fuliginea). Can. J. Bot. 69:140-146.

23. Samuels, A. L., Glass, A. D. M., Ehret, D. L., and Menzies, J. G. 1993. The effects of silicon supplementation on cucumber fruit: Changes in surface characteristics. Ann. Bot. 72:433-440.

24. Savant, N. K., Snyder, G. H., and Datnoff, L. E. 1997. Silicon management and sustainable rice production. Adv. Agron. 58:151-199.

25. Seebold, K. W., Datnoff, L. E., Correa-Victoria, F. J., Kucharek, T. A., and Snyder, G. H. 2000. Effect of silicon rate and host resistance on blast, scald, and yield of upland rice. Plant Dis. 84:871-876.

26. Seebold, K. W., Kucharek, T. A., Datnoff, L. E., Correa-Victoria, F. J., and Marchetti, M. A. 2001. The influence of silicon on components of resistance to blast in susceptible, partially resistant, and resistant culti- 
vars of rice. Phytopathology 91:63-69.

27. Soni, S., Kaufman, P. B., and Jones, R. A. 1972. Electron microprobe analysis of the distribution of silicon and other elements in rice leaf epidermis. Bot. Gaz. 133:66-72.

28. Volk, R. J., Kahn, R. P., and Weintraub, R. L. 1958. Silicon content of the rice plant as a factor influencing its resistance to infection by the blast fungus, Pyricularia oryzae. Phytopathology 48:179-184.

29. Yoshida, S., Forno, D. A., Cock, J. H., and Gomez, K. A. 1976. Laboratory Manual for Physiological Studies of Rice. 3rd ed. IRRI Press,
Manila, Philippines.

30. Yoshida, S., Ohnishi, Y., and Kitagishi, K. 1962. Histochemistry of silicon in rice plant. II. Localization of silicon within rice tissues. Soil Sci. Plant Nutr. 8:36-41.

31. Yoshida, S., Ohnishi, Y., and Kitagishi, K. 1962. Histochemistry of silicon in rice plant. III. The presence of cuticle-silica double layer in the epidermal tissue. Soil Sci. Plant Nutr. 8:1-5.

32. Zeyen, R. J. 1982. Applications of in situ microanalysis in understanding disease: X-ray microanalysis. Annu. Rev. Phytopathol. 20:119-142. 